\title{
Biologia reprodutiva da tabarana Salminus hilarii (osteichthyes, characidae) na represa de Três Marias
}

\section{Reproductive biology of Salminus hilarii (osteichthyes, characidae) from a Brazilian man-made lake}

\author{
Dalcio Ricardo de Andrade, ${ }^{*}$ Alexandre Lima Godinho, ${ }^{* *}$ Hugo Pereira Godinho, ${ }^{* * *}$ Eduardo Shimoda****
}

\begin{abstract}
Resumo
Este trabalho teve como objetivo estudar a biologia reprodutiva da tabarana Salminus hilarii, na represa de Três Marias (MG). Foram determinados, a partir de exemplares capturados durante 20 meses, os seguintes parâmetros: comprimento padrão (CP), peso corporal (PC), índices gonadossomático (IGS), hepatossomático (IHS), de gordura abdominal (IGA) e estágio de maturação (em repouso, em maturação, maduro ou esgotado). Verificou-se que o período de reprodução da tabarana se concentra nos meses finais e iniciais do ano, podendo ser classificada como de desova total. Foi avaliado, ainda, o grau de aspereza ao tato das espículas na nadadeira anal dos machos, sendo observados incrementos crescentes conforme avançava o grau de maturação dos exemplares.
\end{abstract}

Palavras-chave: reprodução, Salminus, reservatórios, característica sexual secundária, tabarana.

\begin{abstract}
Reproductive biology of Salminus hilarii (osteichthyes, characidae) from a brazilian man-made lake This work was carried out at Três Marias dam, Minas Gerais State, Brazil, with the aim of studying the male and female reproductive biology of the fish Salminus hilarii in a man-made lake. From fishes captured during the period April/1982 to november/1984 the following results were obtained: the body length, body weight and the indices: gonadossomatic, hepatossomatic and abdominal fat; stages of ovarian development (dormant, in maturation, ripe and spawned or exhausted). It was verified that the spawning period S. hilarii occurred at the end and at the beginning of each year of this study and this fish species could be classified as a total spawner. From the observations of the level of the toughness of the anal fin of male fish (sexual secondary characteristic) it was verified that roughness was more evident in fish with ovaries in advanced maturation stage.
\end{abstract}

Keywords: tabarana, Salminus hilarii, reproduction, fish, reproduction cycle.

\section{Introdução}

Salminus hilarii Valenciennes, 1829, popularmente conhecido como dourado-branco ou tabarana, é caracídeo da subfamília Salminae e de ampla distribuição nas bacias hidrográficas brasileiras (Martins, 1933; Fowler, 1954; Paiva, 1959; Godoy, 1975). Esta subfamília possui um único gênero, Salminus, com poucas espécies (Fowler, 1954). Seus representantes mais conhecidos são peixes potamodrômicos e alguns são importantes na pesca comercial e esportiva. Apesar de sua importância, a biologia reprodutiva do tabarana é pouco estudada, principalmente nos ambientes lênticos formados em barramentos de rios. O objetivo deste trabalho foi determinar o ciclo reprodutivo anual de $S$. Hilarii na represa de Três Marias (MG).

\section{Material e métodos}

Machos e fêmeas de $S$. Hilarii foram capturados mensalmente com redes de emalhar na represa de Três Marias, rio São

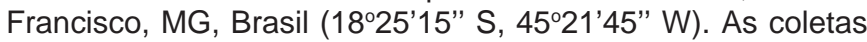
foram realizadas de maio de 1982 a novembro de 1984 , capturando-se o total de 382 exemplares, sendo 169 machos e 213 fêmeas.

A determinação dos estágios gonadais foi realizada mediante a utilização de técnicas histológicas (Dias et al., 1998; West, 1990). As gônadas foram classificadas nos estágios de maturação (recuperação-repouso, em maturação, maduro e esgotado) utilizando-se fragmentos do terço médio da gônada direita de cada exemplar fixados em líquido de Bouin, incluídos em parafina, cortados com $7 \mu \mathrm{m}$ e corados em HE.

* LZNA - CCTA - UENF, Av. Alberto Lamego, 2000 - 28015-620 - Campos dos Goytacazes, RJ.

** Depto. de Morfologia - ICB - UFMG, 31270-000 - Belo Horizonte, MG.

*** Pós-Graduação em Zoologia - PUC/MG.

**** Faculdade de Castelo - Castelo, ES; Universidade Estácio de Sá - Campos dos Goytacazes, RJ. 
Para cada peixe foram obtidos os índices gonadossomático (IGS), de gordura abdominal (IGA) e hepatossomático (IHS) e o fator de condição $(K)$, segundo as fórmulas a seguir:

\begin{tabular}{|c|c|c|c|}
\hline IGS $=$ & $\frac{2 . P G}{P C} \cdot 100$ & $\mathrm{IHS}=$ & $\frac{P F}{P C} \cdot 100$ \\
\hline IGA & $\frac{P G A}{P C} \cdot 100$ & $\mathrm{~K}=$ & $\frac{\mathrm{PC}}{\mathrm{CP}^{3}} \cdot 100$ \\
\hline
\end{tabular}

onde:

$P C=$ peso corporal $(\mathrm{g}) ; \mathrm{CP}=$ comprimento padrão $(\mathrm{cm})$; $P G=$ peso da gônada esquerda (g); $P G C$ = peso da gordura celomática (g); PF = peso do fígado (g);

Determinou-se, ainda, o grau de aspereza ao tato das espículas na nadadeira anal, o qual foi classificado em: ausente/baixo, intermediário e intenso.

Os dados foram processados com auxílio do aplicativo SAEG (SAEG, 1997).

\section{Resultados e discussão}

\section{Anatomia das gônadas}

Os testículos de Salminus hilarii são órgãos pares, alongados, situados ventro-lateralmente a bexiga gasosa. Quando em repouso, são filamentosos e translúcidos. Durante o processo de maturação, aumentam gradualmente de peso, tornandose opacos e branco-avermelhados e atingem seu maior desenvolvimento no final deste processo. Os testículos unemse na extremidade caudal formando um ducto espermático curto que se abre na papila genital. O menor macho com os testículos maduros tinha $19,5 \mathrm{~cm}$ de comprimento-padrão e 122 gramas de peso corporal.

Os ovários também são estruturas pares, alongados, dispostos ao longo da bexiga gasosa e envolvidos pelo mesovário. Em repouso, são delgados e achatados. Durante a maturação, aumentam de peso e sua coloração avermelhada inicial modifica-se gradualmente até tornar-se esverdeada ao final da maturação, fato que corrobora Andrade (1990), Lima et al. (1991) e Teles e Godinho (1997), que descrevem grandes variações que ocorrem nas gônadas durante o ciclo reprodutivo. Os ovários unem-se na extremidade caudal formando um curto oviduto que se abre na papila genital. A menor fêmea madura tinha $20,7 \mathrm{~cm}$ de comprimento-padrão e 147 gramas de peso corporal.

\section{Histologia das gônadas}

Os testículos de $S$. Hilarii são revestidos pelo mesórquio. Logo abaixo deste encontra-se a túnica albugínea de natureza conjuntiva, PAS-positiva, rica em vasos sangüíneos e células musculares lisas. Ela emite ramificações para o interior do órgão envolvendo os túbulos seminíferos. O tecido intersticial, sempre presente, é mais evidente durante o estágio de repouso. A face interna dos túbulos é revestida por células de Sertoli que envolvem as células da linhagem espermatogênica formando os cistos. As células contidas em cada cisto encontram-se no mesmo estágio de desenvolvimento. Ao se romper, o cisto libera seu conteúdo no lume dos túbulos seminíferos. Este lume permanece evidente durante todo o ciclo reprodutivo e, comumente, observa-se secreção acidófila no seu interior.

Os ovários também são revestidos pelo peritônio, constituindose no mesovário. Semelhantemente aos testículos, possuem túnica externa de natureza conjuntiva, rica em vasos sangüíneos e células musculares lisas. Esta túnica emite septos em direção ao lume ovariano, formando as lamelas ovulígeras, nas quais se localizam as células germinativas durante o processo de amadurecimento ovocitário. Este padrão morfológico coincide com obsevações realizadas por Barbieri et al. (1981), Agostinho et al. (1982), Narahara (1983) e Nogueira et al. (1997).

\section{Caracterização morfológica dos estágios de maturação gonadal}

- Recuperação-repouso (estágio 1): ocorre a reorganização da gônada para início de novo ciclo reprodutivo anual. Células reprodutivas residuais e em reabsorção estão presentes na fase inicial deste estágio. $\mathrm{Na}$ fase mais adiantada, os testículos possuem apenas espermatogônias nos cistos, enquanto nos ovários ocorrem ovogônias e ovócitos pré-vitelogênicos.

- Em maturação (estágio 2): caracteriza-se pela presença de células da linhagem germinativa em diferentes fases de desenvolvimento e acúmulo de espermatozóides.

- Maduro (estágio 3): neste estágio, nos testículos encontrase a maior quantidade de espermatozóides e, conseqüentemente, a maior dilatação no lume dos túbulos seminíferos. Nos ovários ocorre nítida predominância de ovócitos vitelogênicos.

- Esgotado (estágio 4): este estágio ocorre após a reprodução e caracteriza-se, nos machos, pela presença de túbulos seminíferos com poucos cistos e lume dilatado, nos quais ocorrem espermatozóides residuais. Nas fêmeas, é caracterizado pela ocorrência de folículos vazios.

\section{Freqüência mensal dos estágios de maturação gonadal}

Os dados referentes à freqüência mensal dos estágios de maturação gonadal encontram-se na Figura 1. Em ambos os sexos, o estágio de recuperação-repouso (estágio 1) foi o mais encontrado, apresentando-se, entretanto, ausente ou em pequena proporção no final e ao início de cada ano.

Considerando todo período de coleta, o estágio em maturação ocorreu, principalmente, ao longo do segundo semestre. Machos e fêmeas maduros (estágio 3) ocorreram de outubro a janeiro. O estágio esgotado (estágio 4) foi observado nos meses de fevereiro a abril, para machos, e de novembro a fevereiro, para fêmeas. A pequena ocorrência deste estágio e também do estágio maduro pode sugerir que os peixes não se reproduzem no local de coleta. Nota-se que o estágio em maturação ocorreu mais precocemente no ano de 1984, para ambos os sexos.

\section{Índices somáticos por estágio de maturação gonadal}

O índice gonadossomático de fêmeas e machos (Figuras 2a e $2 b$, respectivamente) cresceu do recuperação-repouso à 
maturação avançada, decrescendo acentuadamente no esgotado.

O índice de gordura abdominal apresentou valores elevados nos estágios 1 e 2 e decresceu acentuadamente no estágio 3 , tornando a se elevar no estágio 4. Este comportamento, observado em ambos os sexos (fêmeas - Figura 2c, machos - Figura 2d), sugere a participação ativa da gordura abdominal na produção dos gametas.

O índice hepatossomático dos machos mostrou tendência de aumento nos peixes em maturação e maduros (Figura 2f). As fêmeas, por outro lado, não apresentaram variações expressivas deste índice (Figura 2e). O fator de condição (K) em fêmeas apresentou valores mais altos em exemplares em maturação, decrescendo a seguir nos estágios maduro e esgotado (Figura 2g). Em machos, o fator de condição mais alto foi observado em peixes em repouso (Figura $2 \mathrm{~h}$ ).
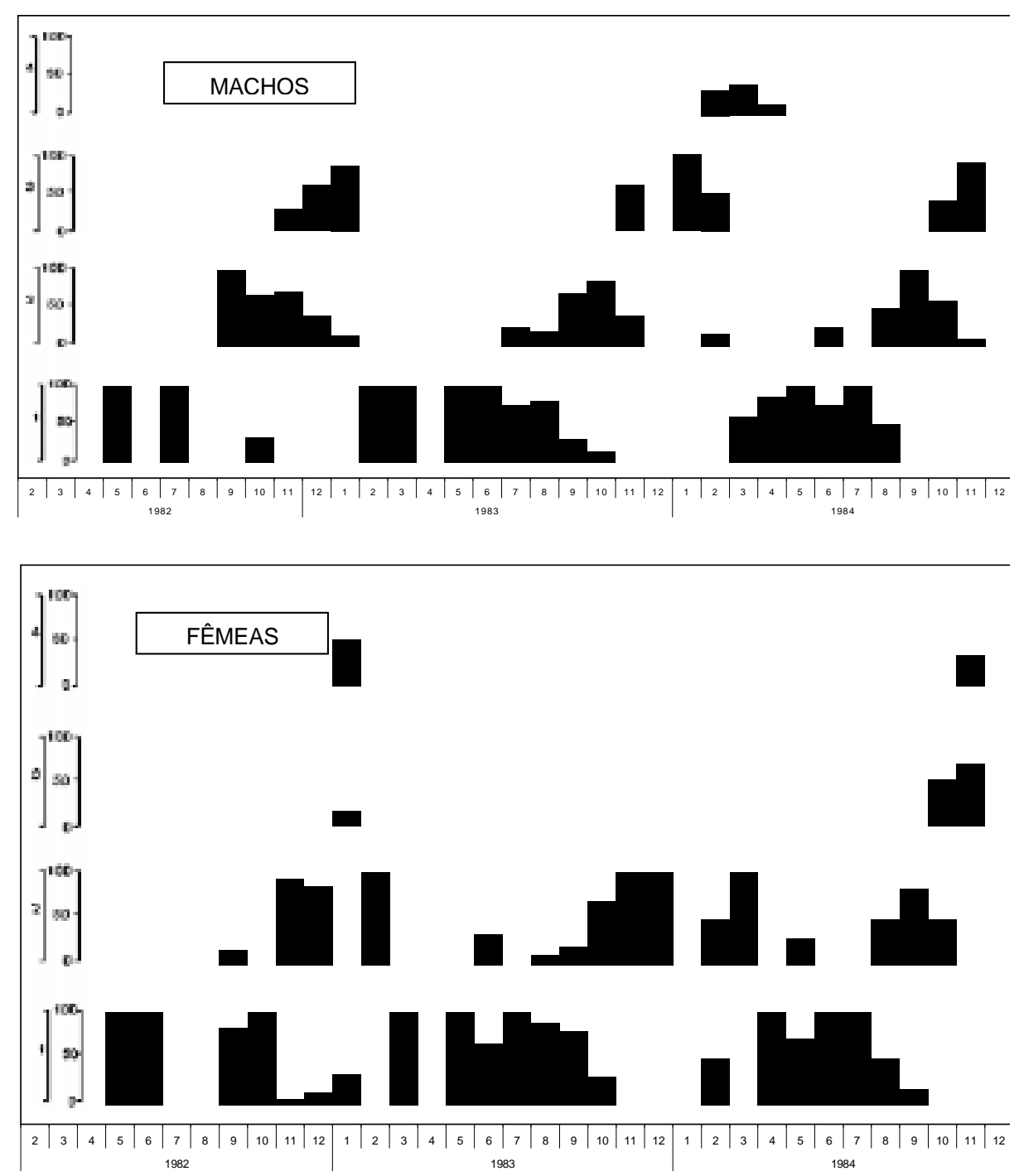

Figura 1: Freqüência mensal dos estágios de maturação gonadal em machos e fêmeas de tabarana
Espículas na nadadeira anal foram encontradas apenas em machos. A variação do grau de aspereza das espículas ao tato, bem como sua freqüência em relação aos estágios de maturação gonadal encontram-se na Figura 3. Cerca de $90 \%$ dos peixes no estágio $1,60 \%$ no início do estágio 2 (referido por alguns autores como maturação inicial ou estágio $2 \mathrm{~A}$ ) e $15 \%$ no estágio 4 não apresentaram espículas (85\% apresentaram baixo grau de aspereza). Todos os exemplares nos estágio 2 avançado (considerado por alguns autores como 2B) e 3 apresentaram espículas. O grau de aspereza e a freqüência de exemplares com espículas aumentaram com o avançar da maturação, atingindo o máximo em peixes maduros (Figura 3).

A ocorrência de espículas em nadadeiras tem sido relatada em algumas espécie de characídeos tais como Salminus maxillosus (Morais Filho e Scubart, 1955; Lima et al., 1986),

Salminus brasiliensis, Brycon lundii (Sato et al., 1988) e Astyanax bimaculatus (Andrade et al., 1984). A presença de espículas é considerada como característica sexual secundária temporária, que aparece em diversas espécies de peixes tetragonopterineos (Ihering e Azevedo, 1936), Salminus maxillosus (Morais Filho e Schobart, 1955; Lima et al., 1986) somente no período de reprodução e apenas nos machos, apesar de já ter sido observada em fêmeas de Tetragonopterineos (Ihering e Azevedo, 1936) e de Astyanax bimaculatus (obs. pes.). Andrade et al. (1984) consta-taram, em machos de Astyanax bimaculatus criados em cativeiro, a presença desta característica ao longo de todo o ano. Em Salminus maxillosus as espículas aparecem na fase mais avançada de maturação (Lima et al., 1986; Morais Filho e Schubart, 1955) e alcançam sua maior diferenciação no estágio maduro (Lima et al., 1986). Em Salminus hilarii as espículas da nadadeira anal ocorreram em diferentes graus de intensidade em todos os estágios de maturação gonadal apenas nos machos. Nesta espécie, ao que parece, esta característica é percebida ao tato em estágios mais precoces da maturação gonadal do que em Salminus maxillosus, no qual elas ocorrem somente a partir de estágios mais avançados do ciclo reprodutivo (Lima et al., 1986). 


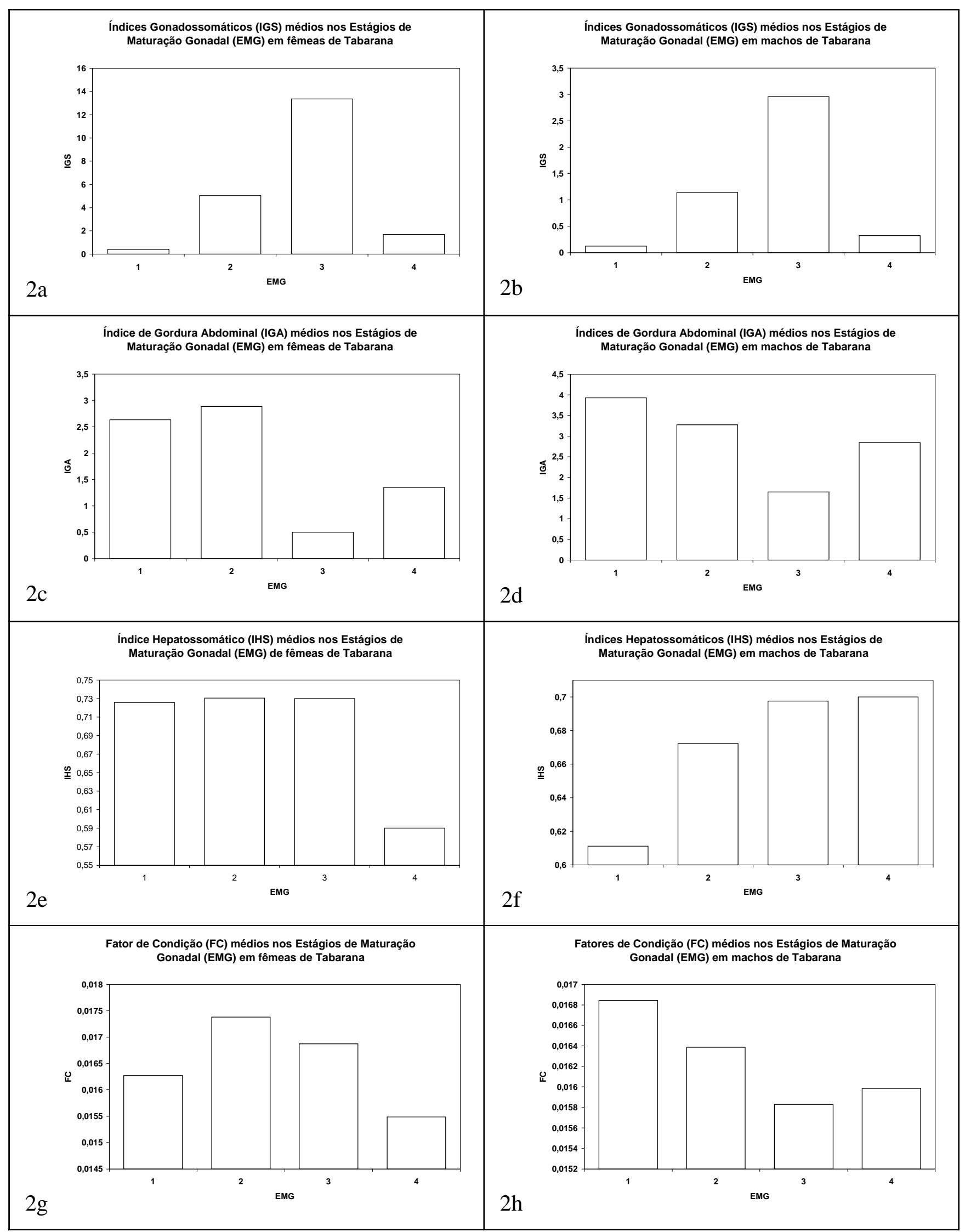

Figura 2: Índices somáticos por estágio de maturação gonadal 
A freqüência de ocorrência das espículas e o seu grau de aspereza ao tato, que grosso modo refletem o tamanho e a quantidade de espículas, aumentaram ao longo do processo de amadurecimento testicular e atingiram o máximo nos exemplares em maturação avançada. Após a reprodução, a freqüência e a aspereza das espículas diminuíram a tal ponto que nos exemplares em recuperação-repouso praticamente não foram observadas.

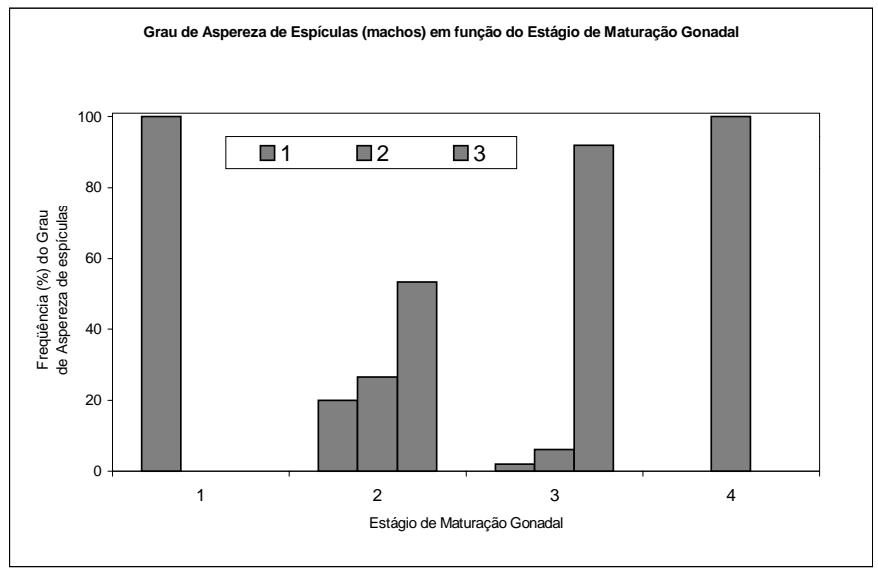

Figura 3: Grau de aspereza das espículas em machos de tabarana nos estágios de maturação (1-ausente/baixo; 2-intermediário; 3-intenso).

\section{Índices somáticos mensais}

O índice gonadossomático (IGS) de fêmeas e de machos (Figura 4a) mostrou variação cíclica evidente. Os valores mais altos ocorreram entre novembro e janeiro e os mais baixos, de modo geral, entre abril e setembro.

Para ambos os sexos os valores mais baixos do índice de gordura abdominal (IGA) (Figura 4b) são observados nos períodos de IGS alto. Nas fêmeas, os valores mais elevados do IGA precederam os picos de IGS e suas médias aumentaram ao longo dos anos de estudo.

Para o índice hepatossomático (IHS) não foi detectado padrão de variação sazonal em nenhum dos sexos e nem relação com os demais índices (Figura 4c).

Os fatores de condição não mostraram variação cíclica evidente (Figura 4). Não foi observada relação evidente entre os fatores de condição e os demais índices.

\section{Período e local de reprodução}

Informações sobre época e local de reprodução da tabarana são fornecidas por Ihering (1929), Magalhães (1931) e Godoy (1935). O último cita que no rio Mogi-Guaçu o S. Hilarii reproduz-se, geralmente, entre dezembro e janeiro, época de chuvas abundantes, das cheias do rio e altas temperaturas da água. Ainda segundo ele, esta espécie desova na dinâmica fluvial. Magalhães (1931) observou, no começo do verão e das enchentes, desovas de tabaranas que eram realizadas em cardumes nas várzeas de água clara com pouca corrente e profundidade.

Chama atenção a captura de duas fêmeas que apresentaram ovócitos com núcleo deslocado o que é característico da maturação gonadal ou ovocitária final que ocorre poucas horas antes da desova. A tabarana é considerada peixe reofílico e acredita-se que não desovarem em ambientes de águas lênticas como, por exemplo, em águas de reservatórios. Neste caso, a tabarana poderia ser capaz de abandonar a represa poucas horas antes do ato reprodutivo, o que pode então representar que esta espécie necessita distância migratória relativamente pequena, quando comparada às informações disponíveis até o presente para os dourados e curimbatás, para completar o seu processo de maturação gonadal.

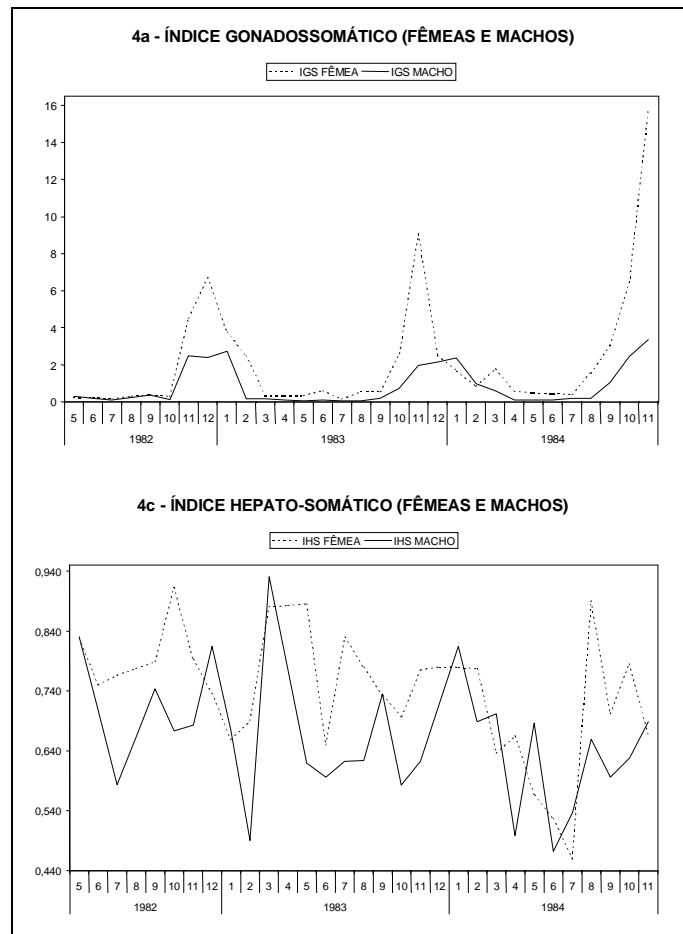

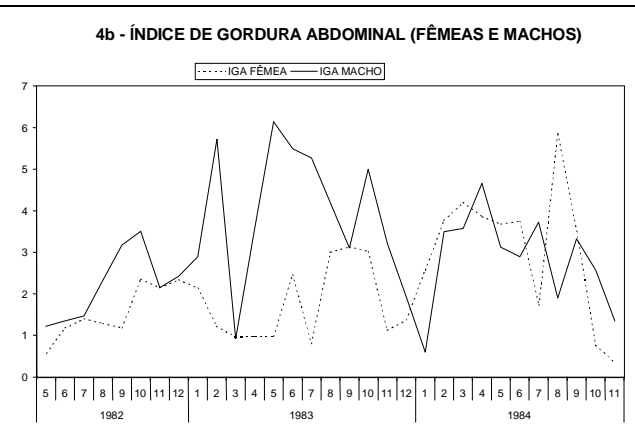

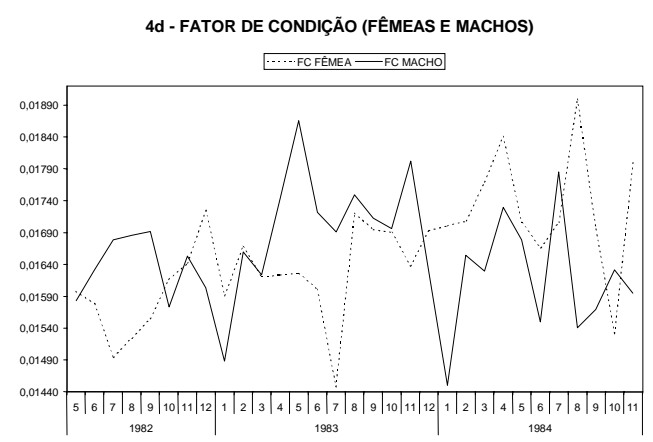

Figura 4: Índices somáticos mensais 


\section{Conclusões}

1-A tabarana Salminus hilarii é uma espécie de peixe de desova total, com variação cíclica anual e período de desova compreendido entre os meses de outubro a fevereiro.

2 -Conforme ocorre a maturação gonadal nos peixes, verificase intenso aumento nos valores de índice gonadossomático, sendo observados valores máximos em exemplares maduros.
3 -Durante as fases anteriores ao estágio maduro, progressivamente ocorre aumento no índice de gordura abdominal, verificando-se abrupta redução do índice em peixes maduros, sugerindo participação desta gordura abdominal no desenvolvimento dos gametas.

4 -O grau de aspereza das espículas da nadadeira anal em machos se torna mais intenso conforme ocorre a maturação dos mesmos, podendo este ser uma característica de dimorfismo sexual e um indicador do grau de maturação dos machos de tabarana.

\section{Agradecimentos}

- Ao CNPq/UFV, pelo auxílio finaceiro.

- À CODEVASF (Estação de Piscicultura de Três Marias), pela captura dos peixes.

\section{Referências}

Agostinho, A. A. Reprodução de fêmeas de Plecostomus commersonii (Valenciennes, 1840) (Osteichthyes, Loricariidae) e suas relações com fatores abióticos. 1979. 76 f. Tese (Mestrado) Universidade Federal do Paraná, 1979.

AGOSTINHO, A. A.; NARAHARA, M. Y:; GODINHO, H. P. Morfologia dos ovários de Plecostomus commersonii (Valenceinne, 1840) Osteichthyes-Loricariidae: desenvolvimento dos ovócitos e escala de maturidade. Rev. Bras. Biol., v. 42, p. 71-77, 1982.

AGOSTINHO, A. A.; NARAHARA, M. Y.; GODINHO, H. M. Morfologia dos ovários de Plecostomus commersonii (Valenciennes, 1840) Osteichthyes - Loricariidae: desenvolvimento dos ovócitos e escala de maturidade. Rev. Bras. Biol., v. 44, n. 1, p. 31-36, 1984.

ANDRADE. D. R. Biologia reprodutiva da manjuba Curimatella lepidura Eigenmann e Eignmann, 1889 (Pisces, Curimatidae) da represa de Três Marias, rio São Francisco, MG. 1990. 217 f. Tese (Doutorado em Morfologia) - Universidade Federal de Minas Gerais, 1990.

ANDRADE, D. R.; GODINHO, H. P. Annual reproductive cycle of the Brazilian Teleost fish Leporinus silvestrii (Boulenger, 1902). Arch. Biol., v. 94, p. 1-14, 1983.

ANDRADE, D. R.; MENIN, E.; RIBEIRO, S. P. Periodicidade da característica sexual secundária em Astyanax bimaculatus (Linnaeus, 1758) Pisces, Characidae. Rev. Seiva, v. 44, n. 93, p. 9-12, 1984.

BARBIERI, G.; BARBIERI, M. C. Reprodução de Gymnotus carapo (Linnaeus, 1758) na represa do Lobo (SP). Morfologia e histologia do ovário. Variação sazonal. (teleostei, Gymnotidae). Rev. Bras. Biol., v. 45, n. 1,2, p. 2-3. 1985.

BARBIERI, G.; BARBIERI, M. C.; MARINS, M. A. Sobre a anatomia e histologia de ovário de Geophagus brasiliensis (Quoy e Gaimard, 1824) na represa do Lobo, SP. Rev. Bras. Biol., v. 41, n. 1, p. 169-173, 1981.

BRITSKI, H. B.; SATO, Y.; ROSA, A. B. S. Manual de identificação de peixes da região de Três Marias, com chaves de identificação os peixes da bacia do São Francisco. 2. ed. Brasília, DF: Câmara dos Deputados, Coordenação de publicações - CODEVASF, Divisão de Piscicultura e Pesca, 1986. $115 \mathrm{p}$.

CHAVES, P. T. C.; VAZZOLER, A. E. A. Aspectos biológicos de peixes amazônicos. II - Anatomia microscópica de ovários: escala de maturidade e tipo de desova das espécies do gênero Semaprochilodus, Rev. Bras. Biol., v. 44, n. 3, p. 347-359, 1984.

DIAS, J. F.; PERES-RIOS, E.; CHAVES, P. T. C.; ROSSIWONGTSCHOWSKI, C.L.D.B. Análise macroscópica dos ovários de teleósteos: problemas de classificação e recomendações de procedimentos. Rev. Brasil. Biol, v. 58, p. 55-69, 1998.
GODINHO, H. P. Reprodução de peixes da represa de Três Marias, MG. Inf. Agrop., v. 10, n. 40, p. 29-34, 1984.

GODOY, M. P. Peixes do Brasil; subordem Characoidei, bacia do rio Mogi Guassu. Piracicaba, Franciscana, 1975. 4v. Rev. Bras. Biol., v. 45, n. 1,2, p. 3-2, 1985.

IHERING, R. V.; AZEVEDO, P. As piabas dos açudes nordestinos (Characidae, Tetragonopterinae). Arch. Inst. Biol., v. 7, n. 3, p. 75-110, 1936.

IHERING. R. V.; PENTEADO, A. C. Idade e crescimento da tabarana (Salminus hilariii), pelo estudo das escamas. Rev. Biol. Hyg., n. 2, p. 212, 1931.

LIMA, R. V. A.; BERNARDINO, G.; VAL-SELLA, M. V.; FAVA-DEMORAES, F.; SCHEME, R. A.;BORELLA, M .I. Tecido germinativo ovariano e ciclo reprodutivo de pacus (Piaractus mesopotamicus Holmberg 1887) mantidos em cativeiro. B. Téc. CEPTA, v. 4, p. 1-46, 1991.

LIMA, R. L. V. A.; VAL-SELLA, M. V.; TORQUATO, V. C. Organização e desenvolvimento das gônadas do dourado (Salminus maxilosus Val.) durante o ciclo reprodutivo. 1986.

MAGALHÃES, A. C. Monografia Brazileira de peixes fluviais. São Paulo, Graphicars, 1931.260 p.

MARTINS, U. B. A tabarana. Almanaque Agrícola Brasileiro. 19331934. p. 255-268.

MORAIS-FILHO, M. B.; SCHUBART, O. Contribuição ao estudo do dourado (Salminus maxilosus Val.) do rio Mogi-Guassu (Pisces, Characidae). São Paulo: Divisão de Caça e Pesca, 1955. 143 p.

NARAHARA, Y. The funcional morphology of teleost gonads. In: Hoar, W. S.; Randall, D. J.; Donaldson, E. M. (Ed.) Fish Physiology. London: Academic Press, v. 9 A, p. 223-275. 1983.

NOGUEIRA, B. P.; BAZZOLI, N.; SANTOS, J. E.; BARROS, M. D. M. Biologia reprodutiva de Bryconops cf. affinis = Creatochanes affinis (Gunther, 1864) (Teleostei: Characiformes) na Lagos do Pantaninho, Lagoa da Prata, Minas Gerais. Bios, v. 5, p. 43-51, 1997.

PAIVA, M. P. Notas sobre o crescimento, tubo digestivo e alimentação da gitubarana, Salminus hilarii, Val. 1829 (pisces, Characidade). Bol. Mus. Nac. Zool., v. 196, p. 1-21, 1959.

SAEG. Viçosa - Universidade Federal de Viçosa, 1997.

TELES, M. E. O.; GODINHO, H. P. Ciclo reprodutivo da Pirambeba Serrasalmus brandtii (teleostei, Characidae) na represa de Três marias, rio São Fancisco. Rev. Bras. Biol, v. 57, p. 177-184. 1997.

WALLACE, R. A. Cellular and dynamic aspects of oocyte growth in teleosts. Amer. Zool., v. 21, p. 325-343, 1981.

WEST, G. methods of assessing ovarian development in fishes: a Review. Aust. J. Mar. Freshwater Res. v. 41, p. 199-222, 1990. 